\title{
Gallbladder Adenosquamous Carcinoma
}

National Cancer Institute

\section{Source}

National Cancer Institute. Gallbladder Adenosquamous Carcinoma. NCI Thesaurus. Code C7356.

A carcinoma that arises from the gallbladder. It is characterized by the presence of glandular and squamous malignant epithelial components. 